\title{
Exploration on Connection Issue between Graduate and Undergraduate Education
}

\author{
Liu Fanghua LouFei Miao Guobin \\ Jiangsu University of Science and Technology \\ School of mechanical engineering \\ ZhenJiang,China \\ loufei_jkd@163.com
}

\begin{abstract}
The present higher education is becoming increasingly popular, in many cases, undergraduate study has already can not meet the needs of themselves and society. In order to enhance research capacity of graduate, cultivate more outstanding fresh undergraduate, master's graduates. This article will focus on the character of major, combined with my experience in undergraduate and graduate teaching to explore the connection issue between graduate and undergraduate education.
\end{abstract}

Keyword- higher education,experience in teaching,connection issue

\section{I . INTRODUCTION}

According to the survey, the number of fresh undergraduate graduates has increased each year, while the number of postgraduate examinations participants each year also showed an increasing state. However, the reasons why they choose to continue to attend graduate school after graduating from college are various, and those can be roughly divided into two categories: first, under pressure to find a job; Second, learn favorite professional knowledge. For whatever reason, we must understand the essential difference between graduate education and undergraduate education. As an excellent university fresh graduates, they should have excellent expertise and can apply it in practical aspects to some extent, only in this way can they be talent which the state and society needs. Graduate training is focused on research capacity, which can be used to find and solve issues through a series of measures. For two different training objectives, take effective solution to deal with the connection issue between graduate and undergraduate education is particularly important [1] [2].

\section{II . ESTABLISH THE RELEVANT PROFESSIONAL KNOWLEDGE SYSTEM}

Many undergraduate students can not tell what their profession is to do, can do, even which direction they will develop at the time of graduation, which is very sad . Therefore, the possibility of establishing their own relevant professional knowledge system learned during college is particularly important . Each high school graduates choose their schools and professional after some careful consideration, however, many students did not have a thorough understanding of the profession they will learn at that time. When they entered the university formally and began to read for this profession really, they may know their profession not the same as before . At this time , they need teachers give proper guidance to help them develop the architecture of their major at different times. This enables students to grasp the overall situation of this profession, sorted out the connection between each discipline within the profession and the field and scope where the profession would be applied to. To establish such a knowledge hierarchy is not as simple as open a lecture to draw tree diagram on the blackboard to explain the relationship between various disciplines, because the students do not understand what the discipline you said is and the contents of it at that time , may be they just has a shallow understanding literally. The formation of knowledge system is not happen overnight , but formed in the continuous learning and thinking. Assume that each specialized course teacher is not simple to teach their subject knowledge in their teaching process, but integrate curricula which students have got it to some extent and give some guidance about the content they will learn. Then , after a period of study , students would have a comprehensive understanding of the profession, have mastered ability to understand various knowledge and make an effective plan for development direction in future .

When students are able to establish the relevant knowledge system, they will be able to integrate what they have learned and be good at grasp the relationship between disciplines. Due to the scope of knowledge studied during university learning is extensive relatively, students can choose a part of that to have a strong focus on , and that part would provides an objective and direction to graduate study in future. During graduate study, learning and research is directed in one direction, contents of the course are mostly introductory, many problems need to be solved by their own hands, and the width of profession is reduced largely, but need to have a further breakthrough. Therefore, students also need to establish knowledge system of relevant profession during graduate study. The knowledge system established during undergraduate helps students choose their research direction , then the one established during postgraduate helps students researching in depth effectively , developing and enhancing research capabilities [3] [4].

In order to establish knowledge system of relevant profession, I focused on start with the following aspects in teaching.

Firstly , make the best use of effective resources provided by the school to encourage undergraduate 
students to take part in a professional lectures arranged by college, in order to have a fully understanding of the characteristics of profession and academic architecture.

Secondly . adjust our teaching methods, do not scripted by PPT blindly, but combined with writing on the blackboard, and mobilize the enthusiasm of the students fully, encouraging students to think. During teaching process, I focus on the combination between disciplines and a certain degree of expansion, and encourage students to learn some more in-depth expertise in their spare time.

Thirdly, with regard to the practive links arranged by college such as curriculum design , engineering practice, discipline experiment and so on , we should take that seriously and required strictly. Helping students using the knowledge they learned in the design and practice integrally. Although the results of the design and practice exist certain discrepancies between reality, that cultivate students' ability to grasp the issues from the whole situation.

Fourthly, as a mentor of graduate students, I advance guide prospective graduate students to study and work, so that they exposure to graduate learning mode as early as possible, and get successful completion of the connection of two phases.

Through the efforts of the above several aspects during the process of my teaching and postgraduate student management in management has received a lot of effects, manifested in the following aspects.

Firstly,by studying curricula like $<$ control engineering foundation $>$ and < Electric Machine >, many students not only master the essentials of knowledge related to the course, but also capable of digest that, and integrate the correct learning method and discipline thinking into the studying of other curricula.

Secondly, through communicating and activity guiding, students could in a positive attitude towards learning, take the initiative to learn some common engineering software (such as Pro/E, Ansys, Adams, Matlab, etc.), and grasp computer knowledge expertly. All of these could take subsidiary function when they research professional knowledge.

Thirdly , communication between students and I turn to frequent, some prospective graduate students have been involved in research before formal admission and give full play to their talent. They adopt to postgraduate teaching mode advance, so that cause the good condition of the connection between graduate and undergraduate teaching. Research project has been not just equal to fulfill a task simply, but a process of striving for their own objective.

\section{III.CULTIVATE DISCIPLINE INTEREST}

Shakespeare said : knowledge must be in line with their own interests benefit. Interest can stimulate one`s desire to learn new knowledge, therefore, to devote students' professional interest during university education is important particularly. When students has a strong interest in their profession, they would have a further learning of professional knowledge. Then they would choose a most interesting direction to research in-depth, the direction they chosen would be likely to be their research direction during graduate period.

In terms of mechanical profession, this is a typica $l$ engineering major that has high requirement of the ability of advance mathematics, physics and compu ter graphics. Engineering course majors have more ap plicability not simply blindly learning theory, but foc us on combining practice and theory. All of the cont ents, whether as small as a simple mechanical design or large as final completion of a project, could get the desired results through calculation, simulation and experiment repeatedly. Therefore, to establish subject interest based on the tedious research process is im portant particularly. Students could have the motivatio $\mathrm{n}$ to overcome challenges even if the work is tedious or failure repeatedly, when they were interested in $t$ heir research [5].

To foster academic interest, I used the following measures in the usual process of teaching and mentoring graduate students:

Firstly, layout some homework regularly to encourage students to think more and be more initiative. Then communicate with them about the issues arising during the study actively. Although knowledge of undergraduate students not as comprehensive as graduate students, but they would enhance their research capacity in the process of study and solve issues, which is good for their studying during graduate period in future.

Secondly, graduate learning is transitory. For those newly enrolled graduate students, arrange them together with experienced one to add to scientific research, and choose their interested direction for them to study in deep. May be there would exist incommensurate situation in the beginning, that could help them entering the state of graduate learning quickly in fact.

\section{IV.GUIDE "INNOVATION PLAN" TRAINING COMPREHENSION ABILITY}

Since "undergraduate innovation plan", "graduate student innovation plan" carried out by our school, has been received by the majority of teachers and students. Many students were very enthusiastic asked to participate "innovation plan" actively, the number of items increased every year. "Innovation" is a conceptual process characterized by new ideas, new inventions and new description, which originated in Latin, the original intent can be conclude as three levels: first, update; second, to create something new; Third, change. Innovation is a human-specific cognitive ability and practice ability, is a senior manifestations of subjective initiative of human and is inexhaustible power to promote national progress and social development. Guiding "innovation" is aims to explore students' potential of scientific research, to inspire students to express their professional ideas adequately, to do some further research of some unique problems combined with knowledge from book and living practice, 
and then put these ideas into practice. Thus, students who experienced by "undergraduate innovation plan" would benefited a lot whether attend graduate school or join in work in future.

Influence of connection graduate and undergraduate education can be shown as follow through guiding "innovation plan".

Firstly, "Innovative programs" almost be carried o ut at college junior, students hang together and study assiduously. The ability to study and solve problems could be cultivated at that time, and build the foun dation of research during postgraduate learning in fut ure.

Secondly, most of the project students met during "Innovative programs" are their interests or their ow $\mathrm{n}$ research, that mobilize the positivity of students to a great extent, and create hard working learning at mosphere for undergraduate study in advance.

Thirdly, communication between students and teac hers has been increased, many students contacted thei $r$ interested project and relevant teacher through the platform of "undergraduate innovation plan". Then th ey finished their final design and graduate research 0 $\mathrm{f}$ related projects under the help of that teacher. Stud ents could form a complete knowledge system after 4 to 5 years learning, so that enhance the efficiency of postgraduate teaching.

Fourthly, graduate and undergraduate students could communicate with each other through the " innovative program ." Undergraduate students could appreciate the characteristics of graduate teaching in advance through contact with their subjects. On the other hand, graduate students could pay some simple tasks to completed by undergraduate to improve work efficiency. That would formed a collaborative relationship for mutual benefits finally.

The design and manufacture process of obstacle crossing robot during "undergraduate innovation plan" can be shown as figure 1 .

And the Improved version model machine wheel leg type ground movement robot can be shown as figure 2 .

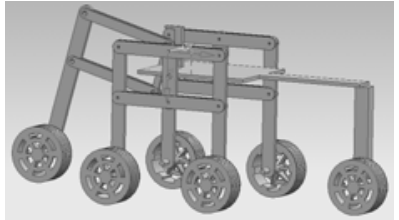

(a) draw three dimensional figure

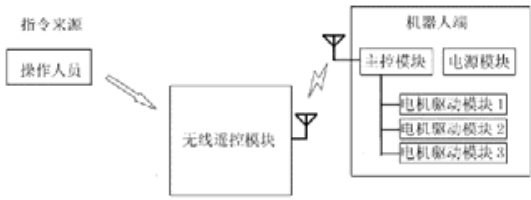

(b) design of control system principle

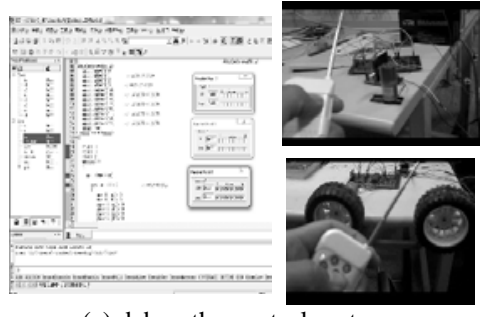

(c) debug the control system

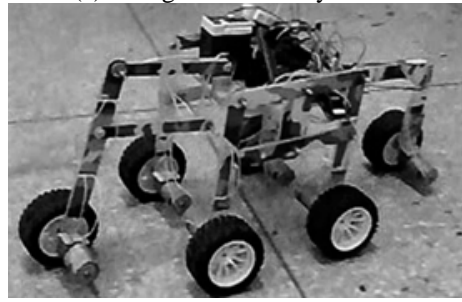

(d) run the whole machine

Figure 1. manufacture process of obstacle crossing robot

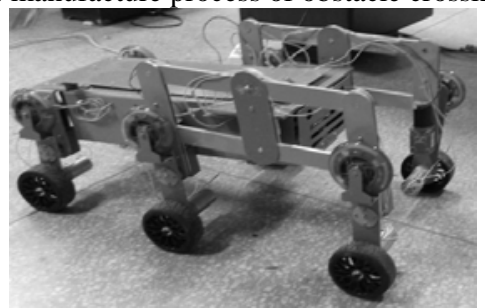

Figure 2. model machine wheel leg type ground movement robot

Contemporary college students, graduate students are the main force to promote the progress of social science. Therefore, to foster innovation is not only in order to solve the connection issue between graduate and undergraduate education, but also has important contemporary significance.

\section{V.CONCLUSION}

I solve the connection issue between graduate and undergraduate education effectively through implement the strategy introduced above. Mainly in the following aspects.

First, owning to these undergraduate students continue graduate learning in our school, they are familiar with our school's facilities, teachers and teaching methods. And they might have a good performance after entering graduate study, especially those students have been directed through "undergraduate innovation plan" could deal with their graduate studying more ease.

Second, graduate students who has been admitted to our school from another could ether the researching state quickly and strive to complete relevant research tasks actively under my guidance.

[1] Zhang Lei , Research Undergraduate - Graduate Education Convergence Model to Explore, Journal of Southeast University, pp.127-130,July 2013

[2] Chen Tingzhu, Discussion on undergraduate education and postgraduate education of convergence, ACADEMIC DEGREES \& GRADUATE EDUCATION，pp.32-34, 2001(7)

[3] William A.Wulf."The Urgency of Engineering EducationReform". 
The Bridge . 1998

[4] Duderstadt J. J.Engineering for a Changing World:A Roadmap to

the Future of Engineering Practice, Research, and Education. .

2008

[5] Siegfried,John J.Trends in undergraduate economics degrees,

1991-2002. The Journal of Economic Education . 2003 